\title{
Photoexcitation dynamics of nitric oxide bound ferric myoglobin probed by femtosecond IR spectroscopy
}

\author{
Jaeheung Park ${ }^{1}$, Taegon Lee ${ }^{1}$, Jaehun Park ${ }^{2}$, and Manho Lim ${ }^{1 *}$ \\ ${ }^{1}$ Department of Chemistry and Chemistry Institute for Functional Materials, Pusan National \\ University, Busan 609-735 Korea \\ ${ }^{2}$ Pohang Accelerator Laboratory, Pohang 790-784 Korea
}

\begin{abstract}
Time-resolved vibrational spectra show that photolysis quantum yield of NO bound ferric myoglobin is smaller than 0.86 , the deligated $\mathrm{NO}$ geminately rebinds with subnanosecond time scale, and the rebinding kinetics depends on protein conformation.
\end{abstract}

\section{Introduction}

Nitric oxide (NO) has been found to perform a number of physiological functions such as smooth muscle relaxation, platelet inhibition, neurotransmission, immune regulation, and penile erection. Much NO's biological function comes from its interactions with heme proteins, such as cytochrome c oxidase, myoglobin $(\mathrm{Mb})$, hemoglobin, NO synthase enzymes. Recently, it has been revealed that $\mathrm{MbO}_{2}$ plays a role as an NO scavenger, regulating NO level in the cell.[1-3] During the NO scavenging process, ferric $\mathrm{Mb}\left(\mathrm{Mb}^{\mathrm{III}}\right)$ is yielded. Because $\mathrm{Mb}^{\mathrm{III}}$ can bind to $\mathrm{NO}$, it reacts with another $\mathrm{NO}$ molecule to yield ferrous $\mathrm{MbNO}$. Other neutral ligand such as $\mathrm{CO}$ and $\mathrm{O}_{2}$ binds only to ferrous $\mathrm{Mb}$ and anions can bind to ferric heme but $\mathrm{NO}$ can bind both ferrous and ferric heme.

Rebinding dynamics of $\mathrm{NO}$ to ferrous $\mathrm{Mb}$ after photolysis of $\mathrm{MbNO}$ was investigated to probe how protein dynamics is related to its structure and function.[4] Most of photodissociated NO geminately rebinds nonexponentially in $1 \mathrm{~ns}$. Vibrational bands of $\mathrm{NO}$ in $\mathrm{MbNO}$ showed two bands and kinetics of the rebinding of both bands are the same, suggesting that the dynamics of geminate rebinding to ferrous $\mathrm{Mb}$ is conformation independent. Here we extend the previous work and comparatively investigated rebinding dynamics of $\mathrm{NO}$ to ferric $\mathrm{Mb}$ with ferrous one.

\section{Experimental methods}

To prepare $12 \mathrm{mM}$ of $\mathrm{NO}$ bound $\mathrm{Mb}^{\mathrm{III}}\left(\mathrm{Mb}^{\mathrm{III}} \mathrm{NO}\right)$, desired amount of lyophilized horse skeleton $\mathrm{Mb}^{\mathrm{III}}$ was dissolved in $\mathrm{D}_{2} \mathrm{O}$ buffered with $0.4 \mathrm{M}$ potassium phosphate ( $\mathrm{pD} 6.3$ ). The solution was deoxygenated extensively by purging with $\mathrm{N}_{2}$ gas for more than $20 \mathrm{~min}$. The $\mathrm{NO} / \mathrm{N}_{2}$ mixture gas was bubbled through $2 \mathrm{M} \mathrm{NaOH}$ solution to eliminated $\mathrm{NO}_{2}$ produced by oxidation of $\mathrm{NO}$, and then introduced to the deoxygenated $\mathrm{Mb}^{\mathrm{III}}$ solution for short time to ligate only about $50 \%$ of the protein with NO.

Home-built two optical parametric amplifiers (OPA) were used to generate a visible pulse and a mid-IR pulse.[4, 5] Frequency doubling of a signal pulse of one OPA generated a visible pulse at $575 \mathrm{~nm}$ with $3 \mu \mathrm{J}$ of energy and difference frequency mixing of the signal and idler pulses of the other OPA generated a mid IR pulse with ca. $1 \mu \mathrm{J}$ of energy. Mid-IR pulse with a typical spectral 
bandwidth of $180 \mathrm{~cm}^{-1}$ was collected by a curved mirror, filtered by a long pass filter and separated into pump and probe pulse by a wedged $\mathrm{BaF}_{2}$-window. Both IR pump and probe pulses generated in one OPA were used for IR pump-IR probe spectroscopy while blocking the visible pulse from other OPA. For visible pump-mid IR probe spectroscopy, the IR pump pulse was blocked and the IR probe pulse was used with a visible pump pulse. A 64-elements $\mathrm{N}_{2}(1)$-cooled $\mathrm{HgCdTe}$ array detector, mounted in the focal plane of a monochromator, was used to detect the broadband transmitted midIR probe pulse.

\section{Results and Discussion}

Vibrational spectrum of $\mathrm{NO}$ stretching mode of $\mathrm{Mb}^{\mathrm{III}} \mathrm{NO}$ in $\mathrm{D}_{2} \mathrm{O}$ solution at room temperature can be decomposed into two bands, the major one at $1921 \mathrm{~cm}^{-1}(97.7 \%)$ with a full width at half maximum (FWHM) of $9 \mathrm{~cm}^{-1}$ and the minor one at $1902 \mathrm{~cm}^{-1}$ (2.3\%) with a FWHM of $11 \mathrm{~cm}^{-1}$. These bands, denoted to $\mathrm{A}_{0}$ (the minor band) and $\mathrm{A}_{1}$ (the major band), $[6,7]$ have been suggested to arise from the presence of discrete bound-state conformations. It was proposed that the band $\mathrm{A}_{1}$ results from an interaction between the bound $\mathrm{NO}$ and the lone-pair electron on a deprotonated His-64-N $\varepsilon$ and the band $\mathrm{A}_{0}$ from conformation where a His-64 side chain does not interact with $\mathrm{NO}[7,8]$. At cryogenic temperature $A_{1}$ band was found to be at $1927 \mathrm{~cm}^{-1}$ for both sperm whale and horse Mbs.[8] Clearly the position of $A_{1}$ band is more sensitive to the interaction between the His-64 and bound NO than species variation of the protein and the extent of the interaction at cryogenic temperature may be stronger than at room temperature.

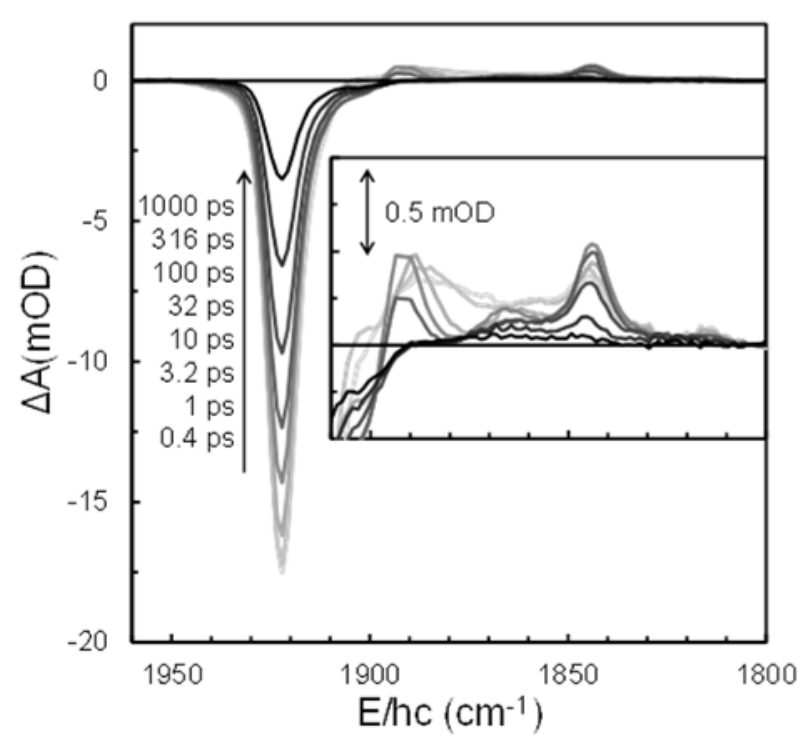

Fig. 1. Time-resolved vibrational spectra after photoexcitation of $\mathrm{Mb}{ }^{\mathrm{III}} \mathrm{NO}$ in $\mathrm{D}_{2} \mathrm{O}$ solution with a $575 \mathrm{~nm}$ pulse at $294 \mathrm{~K}$. Inset is the expanded view to show small but significant new absorption features in lower energy side of the main band.

Figure 1 shows femtosecond vibrational spectra in the region of NO stretching mode after photoexcitation of $\mathrm{Mb}^{\mathrm{III}} \mathrm{NO}$ in $\mathrm{D}_{2} \mathrm{O}$ solution at $294 \mathrm{~K}$ with a $575-\mathrm{nm}$ pulse. The negative-going feature (bleach), appearing faster than the time-resolution of the instrument, is similar to the inverted equilibrium spectrum of $\mathrm{NO}$ stretching mode in $\mathrm{Mb}^{\mathrm{III}} \mathrm{NO}$. It arises from the loss of $\mathrm{Mb}^{\mathrm{III}} \mathrm{NO}$ in the ground NO vibrational state of the ground electronic state of the heme. The spectra show small but significant new absorption features at lower energy side of the main band, in the region of 1920 $1880 \mathrm{~cm}^{-1}$, that can be modeled with two evolving absorption bands. Two bands shift toward higher 
energy and narrow with a time constant of 2 ps, indicating that both bands evolve with thermal relaxation of the heated heme. One band settled at the position of $1893 \mathrm{~cm}^{-1}$ within $2 \mathrm{ps}$ and its amplitude decays with 24 ps. Both the position of the band and the relaxation time suggest that it arises from the vibrationally excited $\mathrm{NO}$ in $\mathrm{Mb}^{\mathrm{III}} \mathrm{NO}$ resulting from rapid electronic and thermal relaxation of the photoexcited $\mathrm{Fe}^{\mathrm{III}} \mathrm{NO}$ without photodissociation of the NO ligand from the heme. The other band, settling at the position of $1917 \mathrm{~cm}^{-1}$ within $2 \mathrm{ps}$, can be further decomposed into two evolving bands: one relaxing into equilibrium spectrum with 2 ps time constant and the other growing with early geminate rebinding of the dissociated NO, settling at $1917 \mathrm{~cm}^{-1}$ and decaying with 7 ps time constant. We assigned the band at $1917 \mathrm{~cm}^{-1}$ to ultrafast rebound $\mathrm{Mb}^{\mathrm{III}} \mathrm{NO}$ with unrelaxed conformation. Absorption features assigned to protein undergoing thermal relaxation without ligand dissociation add up to $14 \%$ of the total bleach, implying that photolysis quantum yield of $\mathrm{Mb}^{\mathrm{III}} \mathrm{NO}$ is smaller than 0.86 . The photodissociated NO undergoes fast geminate recombination with subnanosecond time scale and the rebinding kinetics depends on the conformation of the protein. Geminate rebinding of $\mathrm{NO}$ to $\mathrm{Mb}$ with major conformation shows highly nonexponential kinetics that was described by the stretched exponential function, $0.77 \exp (-$ $\left.(t / 330 \mathrm{ps})^{0.58}+0.09\right)$. The NO rebinding to $\mathrm{Mb}$ with minor conformation is slower than that with the major conformation and exponential, which is exp $(-t / 1.8 \mathrm{~ns})$. There were other new absorption features appearing at $1860-1840 \mathrm{~cm}^{-1}$. They are located at even lower energy side of NO band in the gas phase and thus assigned to the stretching mode of $\mathrm{NO}$ photodissociated from $\mathrm{Mb}^{\mathrm{III}} \mathrm{NO}$ that resides interior of the protein. They decay as NO geminately rebinds and escapes to solvent. As demonstrated, time-resolved vibrational spectra with high sensitivity reveal a rich photophysical and photochemical processes of photoexcited $\mathrm{Mb}^{\mathrm{III}} \mathrm{NO}$.

Acknowledgements. This research was supported by for two years by Pusan National University Research Grant.

\section{References}

1. M. Brunori, Trends Biochem. Sci. 26, 209 (2001).

2. U. Flogel, M. W. Merx, A. Godecke, U. K. M. Decking, and J. Schrader, Proc. Natl. Acad. Sci. U. S. A. 98, 735 (2001).

3. D. J. Garry, A. Meeson, Z. Yan, and R. S. Williams, Cell. Mol. Life Sci. 57, 896 (2000).

4. S. Kim, G. Jin, and M. Lim, J. Phys. Chem. B 108, 20366 (2004).

5. S. Kim, G. Jin, and M. Lim, Bull. Korean Chem. Soc. 24, 1470 (2003).

6. K. Nienhaus, P. Deng, J. M. Kriegl, and G. U. Nienhaus, Biochemistry 42, 9647 (2003).

7. K. Nienhaus, P. Palladino, and G. U. Nienhaus, Biochemistry 47, 935 (2008).

8. L. M. Miller, A. J. Pedraza, and M. R. Chance, Biochemistry 36, 12199 (1997). 